\title{
Ureteric stone management: comparison of ureteroscopy using pneumatic lithotripsy with ureterolithotomy results
}

Nooman H. Saeed

From the Department of Surgery, College of Medicine, University of Mosul. Correspondence: Nooman H. Saeed. Lecturer, Department of Surgery, College of Medicine, University of Mosul, Mosul, Iraq. Email: noomanhadi@yahoo.com.

(Ann Coll Med Mosul 2013; 39 (1): 70-74).

Received: 10 ${ }^{\text {th }}$ Jan. 2012; Accepted: $2^{\text {nd }}$ Oct. 2012.

\section{ABSTRACT}

Objective: The purpose of this study is to compare ureteroscopy using pneumatic lithotripsy with open surgery (ureterolithotomy) in treating ureteric stones regarding the success rate, procedures time, need for post-operative analgesia, duration of hospital stay, and complications rate.

Patients and methods: A prospective study of 90 patients suffering from ureteric stones, referred to the urology center at Al- Jumhori Teaching Hospital in Mosul city between $1^{\text {st }}$ of May $2010-31^{\text {st }}$ of March 2011. Fifty patients were treated by ureteroscopy and 40 patients by ureterolithotomy. Their age and sex distribution was comparable. Results of both treatment modalities were analyzed and compared.

Results: The success rate for ureteroscopy was $90 \%$ and for ureterolithotomy was $97.5 \%$. The procedure time was significantly shorter for ureteroscopy patients (21 minute versus 67 minute). Mean post-operative analgesia was much less for ureteroscopy (1.1 versus 9.5 analgesic injections). Ninety two percent of ureteroscopy patients were discharged at same day of operation with mean hospital stay of 1.12 days compared to 3.5 days for ureterolithotomy group. Complications were reported in $8 \%$ in ureteroscopy and $5 \%$ in ureterolithotomy group.

Conclusion: The success rate of ureteroscopic procedures using pneumatic lithotripsy is comparable to that of ureterolithotomy, but with significantly shorter procedure time, less need for post-operative analgesia, shorter hospital stay, and with no significant increase in the complications rate. These results mean early return to social life and activities, and make ureteroscopy a preferable option for treating ureteric stone when facilities and surgical skills are available.

\section{حصاة الحالب: مقارنة بين علاج حصاة الحالب باستخدام ناظور الحالب وعملية فتح الحالب ورفع الحصاة البحاة}

الههف: مع دخول التقيات العلاجية الحديثة أصبح من المدكن التعامل مع حصاة الحالب بطرق علاجية متعددة. الغرض من هذه

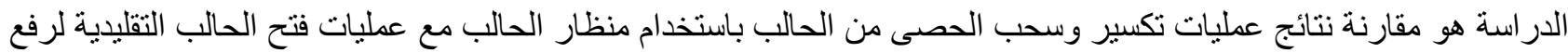

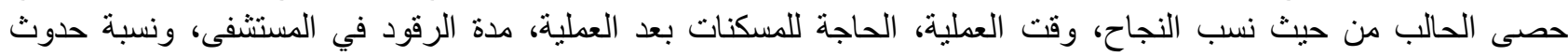
المضاعفات بعد العمليات.

المرضى والطريقة: دراسة مستقبلية شملت (·و) مريضاً يعانون من حصاة الحالب، في مركز جراحة المسالك البولية في

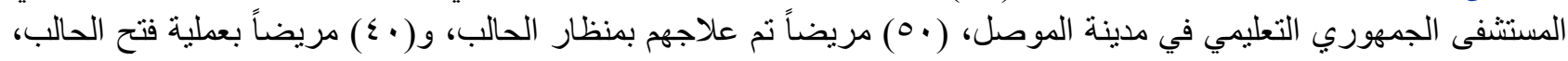
وتم مقارنة النتائج. النتائج: كانت نسبة نجاح الطريقتين العلاجيتين متقاربة، إلا أن وقت العطلية، وكمية المسكنات بعد العملية، ومدة الرقود في

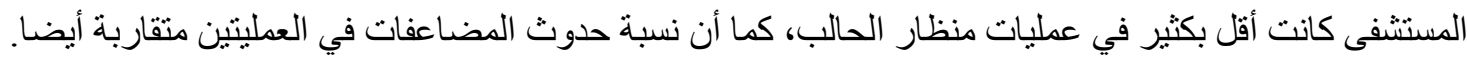

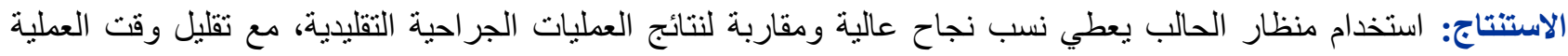

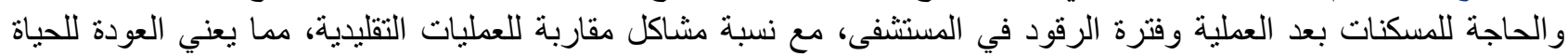
الاعتيادية وممارسة العمل بوقت مبكر. 
U rinary tract stones are the third most common condition affecting the urinary $\operatorname{tract}^{(1)}$. Ambroise Pare is credited with the first account of ureteral calculi in 1564; the first mentioned ureterolithotomy was in 1879 by Thomas Emmet. The practice of ureteroscopy began in 1912, by Hugh Hampton Young ${ }^{(2)}$. Before the 1980s, ureteric stones were managed by open ureterolithotomy ${ }^{(3)}$. Technological developments have drastically changed the management of ureteral calculi in the last two decades ${ }^{(4)}$. The treatment of these calculi has evolved from ureterolithotomy to ureterorenoscopy with endoscopic lithotripsy and extracorporeal shockwave lithotripsy ${ }^{(5-6)}$. Despite the definite success of endourological stone treatment, ongoing questions about the optimum management of ureteric stones remain debated among urologists ${ }^{(7)}$. The aim of this study is to compare ureteroscopic stone management using pneumatic lithotripsy with ureterolithotomy regarding success (stone free) rate, procedures time, need for post-operative analgesia, and duration of hospital stay and complications rate.

\section{PATIENTS AND METHODS}

A prospective study that was conducted on 90 patients suffering from ureteric stones who were referred to the urology center at Al- Jumhori Teaching Hospital in Mosul city between $1^{\text {st }}$ of May $2010-31^{\text {st }}$ of March 2011. Preoperative evaluation included detailed history concentrating on history of previous urinary stone disease and the method(s) of management, physical examination. Laboratory investigations included urine analysis, kidney function tests and $\mathrm{Hb} \%$. Imaging studies included urinary tract ultrasound, kidney ureter and bladder (KUB), intravenous urography (IVU), and non-contrasted tomography (CT scan) of urinary tract when indicated. After defining the indications for surgical intervention, the patients were made aware of the modalities of treatment, their indications, possible complications, and need for follow up. The patients were divided into 2 groups: Those who were treated by ureteroscopy (50 patients), and those who were treated by ureterolithotomy (40 patients). The choice of treatment modality was dependant on the stone size, whether unilateral or bilateral, presence of multiple stones at different levels in the ureter where ureteroscopy is preferred, history of previous urinary stone and its management modality(s), patients age where pediatric size ureteroscope was not available, presence of comorbidities like bleeding tendency where ureteroscopy is preferred, those with hip deformity where lithotomy position to perform ureteroscopy is impossible, and patients preference.

All of the ureteroscopic procedures were performed using the same settings, with semirigid $10 \mathrm{Fr}$ (Karl storz) ureteroscope, under general anesthesia. Ballistic (pneumatic) lithotripsy was used to fragment the stone(s) that were flushed by irrigation fluid, and residual small stones were retrieved with forceps. While for the ureterolithotomy group, the procedures were performed in the classical method according to stones level in the ureter. During either procedure double $\mathrm{J}$ stent insertion was optional. Post operatively the patients were advised to observe their urine output for any possible residual stone passage, and were reevaluated radiologically using urinary tract ultrasound, KUB, (and sometimes urinary tract CT scan in cases with radiolucent stone) to check for stone clearance and to decide for double $\mathrm{J}$ removal for those who needed it one month later. Then the results of both procedures were analyzed and Chi square test was used to compare the results of both treatment modalities with $p$ value considered significant if less than 0.05 .

\section{RESULTS}

For ureteroscopy group the age ranged between 17-71 year (mean 38.64 year), while ureterolithotomy group it ranged between 3- 66 years (mean 39.5 years). The $P$ value was 0.899 . Sex distribution was the same for both groups with $70 \%$ male and $30 \%$ female patients (Figure 1). Of the ureteroscopic group, 20 patients had right , 27 left, and 3 bilateral stones and underwent bilateral procedures at the same session, i.e. 53 ureteroscopic procedures were performed (Figure 2). All of the patients who underwent ureterolithotomy had unilateral stones with 20 right and 20 left sided ureteric stones (Figure 3). The stone location in the ureteroscopy group was 15 upper, $9 \mathrm{mid}$, and 29 lower ureteric stones (three patients had bilateral ureteric stones). While the ureterolithotomy group, 20 patients had upper, 8 mid, and 12 lower ureteric stones (Figure 4). The stones longest diameters for ureteroscopy patients 
ranged between $5-15 \mathrm{~mm}$ (mean $11 \mathrm{~mm}$ ), whereas it ranged between $10-40 \mathrm{~mm}$ with mean of $22 \mathrm{~mm}$ in ureterolithotomy group, $\mathrm{P}$ value is 0.009 . Regarding success rate, for the ureteroscopy patients, 45 patients became stone free, whereas 5 patients failed to get rid of their stones. While the ureterolithotomy group there was only one failure (Figure 5), $P$ value is 0.171 . The operative time for ureteroscopy group range between 10-75 minutes with mean of 21 minutes. For the ureterolithotomy group it ranged between 40-120 minutes with mean of 67 minutes, $P$ value was 0.000 . The ureteroscopy patients who were discharged at the same day of operation needed single paranteral analgesic post operatively and were given oral analgesia on need at home. Those patients who needed longer hospital stay needed more analgesics, the mean was 1.1 injections.

The ureterolithotomy group need for postoperative paranteral analgesia ranged between 3-16 injections (mean of 9.5 injections). $\mathrm{P}$ value is 0.000 . Hospital stay for ureteroscopy patients: 46 patients $(92 \%)$ were discharged at the same day of operation, 4 patients $(8 \%)$ needed longer hospital stay, and the mean was 1.12 days. For ureterolithotomy group the duration ranged between 3- 6 days (mean 3.5 days). $P$ value is 0.000 . Complications were reported in 4 patients $(8 \%)$ in case of ureteroscopic patients which included 2 ureteric mucosal injuries, one ureteral perforation and one post-operative hematuria, and in 2 patients $(5 \%)$ in case of ureterolithotomy which included wound dehiscence and postoperative hematuria, $P$ value is 0.649 (Table 1).

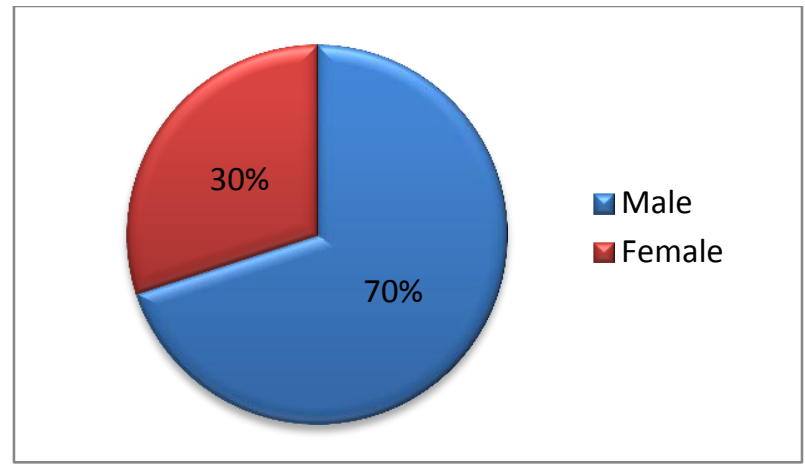

Figure 1. Pie chart showing sex distribution in both groups.

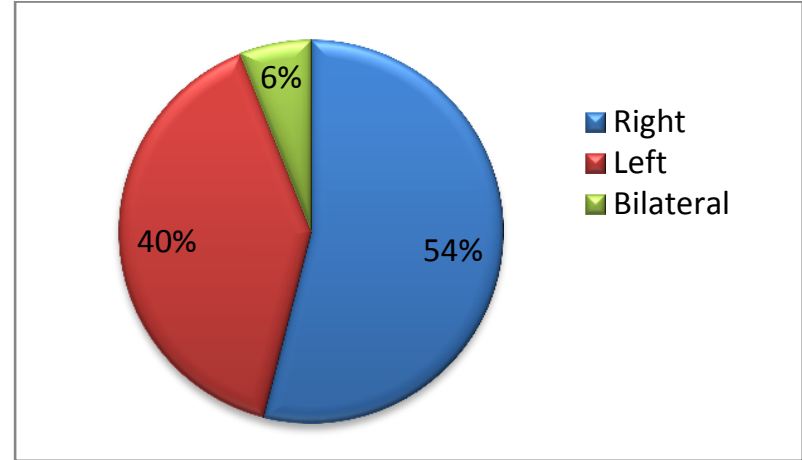

Figure 2. Pie chart showing distribution of the stone side in the ureteroscopy group.

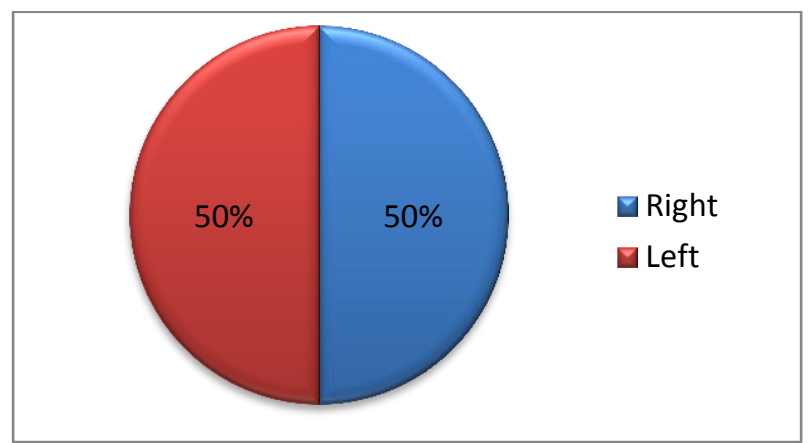

Figure 3. Pie chart showing distribution of the stone side in the ureterolithotomy group.

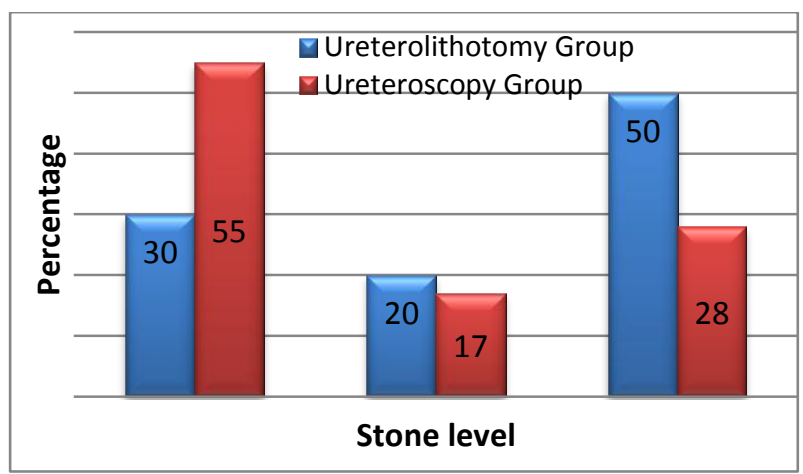

Figure 4. Percentages of lower, mid, and upper ureteric stones.

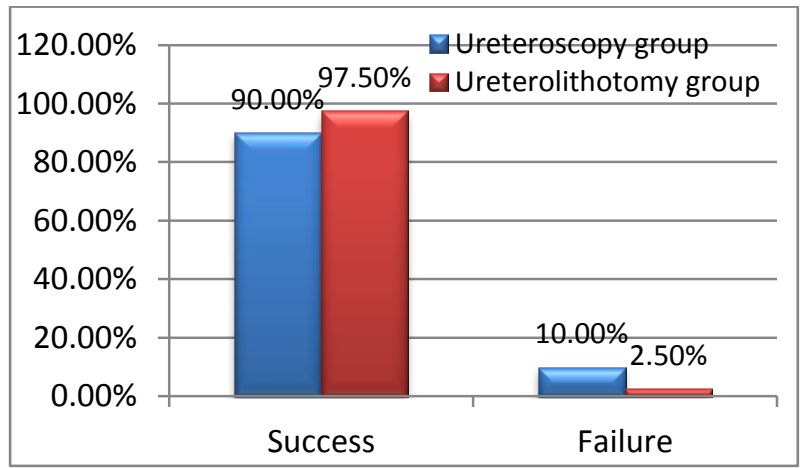

Figure 5. Success vs. failure rate of ureteroscopy and ureterolithotomy group. 
Table 1. Comparison between the ureteroscopy and the ureterolithotomy groups.

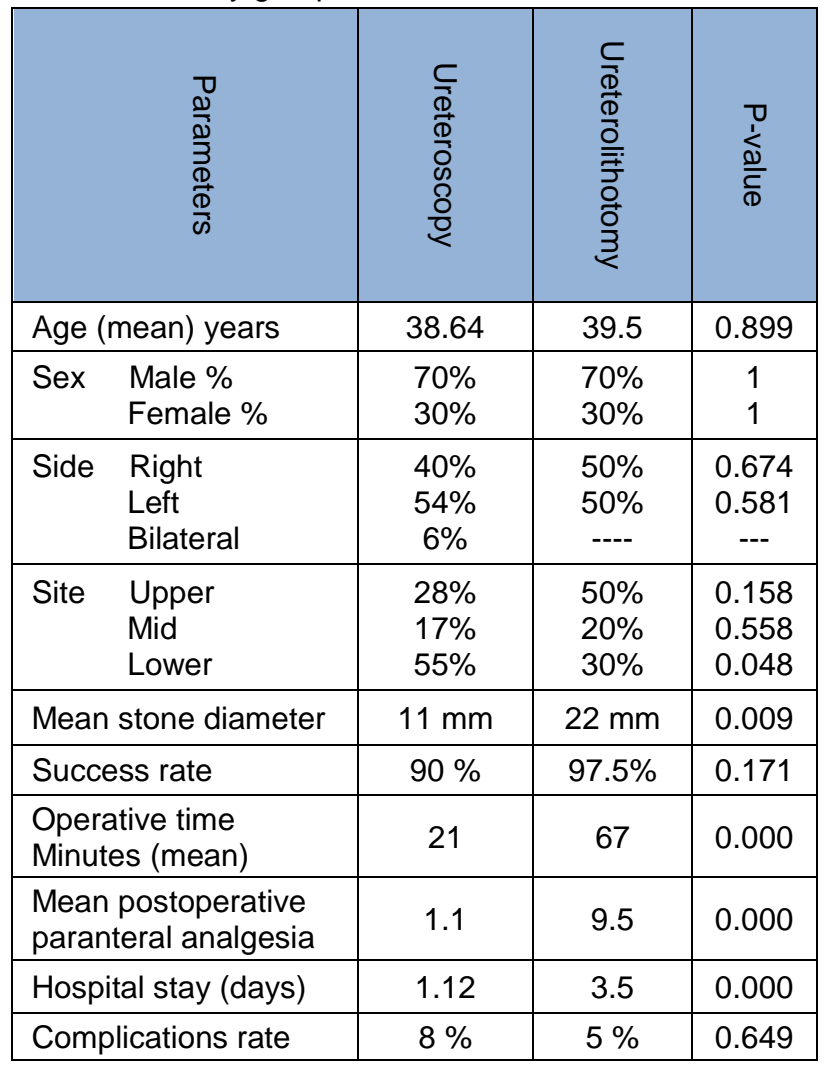

\section{DISCUSSION}

The goal of the surgical treatment of ureteral calculi is to achieve complete stone clearance with minimal attendant morbidity ${ }^{(2)}$. The improvements in surgical technology including the design of the ureteroscope and the lithotripsy technique have greatly augmented the urologists ability to efficiently treat ureteral calculi $^{(8)}$. The morbidity of the incision of ureterolithotomy, the possibility of retained stone fragments, and the ease and success of less invasive techniques have made these procedures relatively uncommon when instruments and surgical experience are available, although it may be an option as a salvage procedure in cases of long-standing ureteral calculi, those inaccessible with endoscopy, those resistant to other modalities of treatment ${ }^{(1,9)}$, or when facilities are not available like some pediatric ureteroscopes were more than $50 \%$ of stones in children are still managed through open surgery ${ }^{(10)}$. The success rate for the ureteroscopy group was $90 \%$, this is comparable with what was found in previous studies where the overall stone-free rate of more than $90 \%$ was achieved, with little drop off in stone-free rates when treating larger stones ${ }^{(11-}$

13). Ballistic (pneumatic) lithotripsy provides fragmentation rates of $90-96 \%$ with the advantages of being simple with safe handling and of low $\operatorname{cost}^{(14-16)}$. For ureterolithotomy success was $97.5 \%$. The efficacy of both treatment modalities was comparable. The mean procedures time was significantly shorter for the ureteroscopy group. Growing experience and the availability of facilities are expected to effectively shorten the procedures time. Ureteroscopic lithotripsy is by far the most expeditious and cost-effective means of clearing ureteral stone burden ${ }^{(17)}$. Post-operative need for paranteral analgesia was significantly lower for the ureteroscopic group, and this is expected due to avoidance of surgical incisions that are usually responsible for more post-operative pain. This is reflected on post-operative hospital stay also, where $92 \%$ of the patients were discharged at the same day of operation, most patients undergoing ureteroscopy are currently treated as outpatients ${ }^{(18-}$ 19). Hospital stay was significantly shorter in the ureteroscopy group(1.12 day versus 3.5 day), so post-operative mobilization, return to work and resumption of normal social activities are expected to be faster. Complications in the ureteroscopy group were encountered in 4 patients $(8 \%)$. The overall complication rates reported with ureteroscopy are 5-9\%, with $1 \%$ significant complications $^{(20-21)}$. There is strong relationship between the complications rate and the equipments used and the expertise of the surgeon ${ }^{(22)}$. With the development of smaller caliber ureteroscopes and the introduction of improved instrumentation, ureteroscopy has evolved into a safer and more efficacious modality for treatment of stones in all locations in the ureter $^{(23)}$. Complications included two ureteric mucosal injuries that needed double $\mathrm{J}$ stent insertion, one ureteric perforation (where Dormia basket was used) that mandated conversion to open surgery and double $\mathrm{J}$ stent was inserted (perforations are successfully treated by ureteral stenting for 2 weeks ${ }^{(20)}$ ), and this was comparable with what was found in previous studies ${ }^{(24)}$, and one patient experiences significant post-operative hematuria that was treated conservatively and did not need blood transfusion. The major acute complication of ureteroscopy is still ureteral avulsion ${ }^{(14,25)}$, which was not experienced in our 
study. Of the ureterolithotomy group, the complications rate was $5 \%$, where one patient developed wound dehiscence that imposed long hospital stay, other patient had post-operative hematuria that was treated conservatively and did not need blood transfusion. Overall, the new advances and treatment options are expected to fulfill a prerequisite of high success rate, together with decreasing procedure times, morbidities, need for analgesia, hospital stay, and with accepted complications rate, which was the case in ureteroscopic pneumatic lithotripsy. In spite of that and although declining, ureterolithotomy will always have its own indications in treating some ureteric stones.

\section{CONCLUSION}

Ureteric stones management using ureteroscopy with pneumatic lithotripsy have success rate comparable to that of ureterolithotomy, but with significant decrease in operative time, postoperative need for analgesia, hospital stay, and no significant difference in the complications rate. These results make ureteroscopy a preferable option when facilities and surgeons experience are available, and ureteroscopic stone manipulation is accessible.

\section{REFERENCES}

1. Emil AT, Jack WM. Smiths General Urology. $17^{\text {th }}$ ed. San Francisco: McGraw-Hills; 2008.p. 246-77.

2. James EL, Brian RM, Andrew PE. Campbell-Walsh Urology. $9^{\text {th }}$ ed. Philadelphia: Saunders; 2007.p.14311507.

3. Khaladkar S, Modi J, Bhansali M, et al. Which is the best option to treat large $(>1.5 \mathrm{~cm})$ midureteric calculi? Journal of laparoendoscopic and advanced surgical techniques 2009;19:501-4.

4. Singh $H$, Tandon V, Dwivedi US, Mahmood M, Hamid A, Kishore G, Singh PB. Management of proximal ureteral stones - comparison of outpatient ureterolithotripsy with in-situ shock wave lithotripsy (SWL). Indian J Urol. 2003; 20:23-7.

5. Huffman JL, Bagley DH, Lyon ES. Treatment of distal ureteral calculi using rigid ureteroscope. Urology 1982; 20: 574-7.

6. Chaussy C, Schmiedt E, Jocham D, Brendel W, Forssmann B, Walther V. First clinical experience with extracorporeally induced destruction of kidney stones by shock waves. J Urol. 1982; 127: 417-20.

7. Gettman MT, Segura JW. Management of ureteric stones: issues and controversies. BJU International 2005; 95: 85-93.
8. Marberger M, Hofbauer J, Turk C, Hobarth K, Albrecht W. Management of ureteric stones. Eur Urol. 1994; 25: 265-72.

9. Muslumanoglu AY, Karadag MA, Tefekli $\mathrm{AH}$, et al. When is open ureterolithotomy indicated for the treatment of ureteral stones?. International journal of urology 2006; 13:1385-8.

10. Hussein N, Gohar M. Pneumatic ureterolithotomy in pediatric and adolescent patients: a ten-year experience at the hospital university sains Malaysia. Singapore Medical Journal 2011; 52: 42-46.

11. Grasso M, Conlin M, Bagley D. Retrograde ureteropyeloscopic treatment of $2 \mathrm{~cm}$ or greater upper urinary tract and minor staghorn calculi. $J$ Urol. 1998;160: 346-351.

12. Pearle MS, Nadler R, Bercowsky E, Chen C, Dunn $\mathrm{M}$, Figenshau RS, et al. Prospective randomized trial comparing shock wave lithotripsy and ureteroscopy for management of distal ureteral calculi. J Urol. 2001;166: 1255-60.

13. Segura JW. Ureteroscopy for lower ureteral stones. Urology 1993; 42: 356-7.

14. Puppo P, Ricciotti G, Bozzo W, Introini C. Primary endoscopic treatment of ureteric calculi. A review of 378 cases. Eur Urol. 1999;36: 48-52.

15. Garg S, Mandal A, Singh S, et al. ureteroscopic laser lithotripsy versus ballistic lithotripsy for treatment of ureteric stones. Urologia internationalis 2009;82:341-5.

16. Tan PK, Tan SM, Consigliere D. Ureteroscopic lithoclast lithotripsy: a cost-effective option. J Endourol. 1998;12: 341-4.

17. Grasso $M$, Beaghler $M$, Loisides $P$. The case of primary endoscopic management of upper urinary tract calculi: cost and outcome assessment of 112 primary ureteral calculi. Urology 1995; 45: 372-6.

18. Prabhakar M. Retrograde ureteroscopic Intrarenal surgery for large $(1.6-3.5 \mathrm{~cm})$ upper ureteric/renal calculus. Indian journal of urology 2010; 26:46-49.

19. Lotan Y, Gettman MT, Roehrborn CG, Cadeddu JA, Pearle MS. Management of ureteral calculi: a cost comparison and decision making analysis. J Urol. 2002; 167: 1621-9.

20. Ferraro RF, Abraham VE, Cohen TD, Preminger GM. A new generation of semirigid fiberoptic ureteroscopes. J Endourol. 1999; 13: 35-40.

21. Harmon WJ, Sershon PD, Blute ML, Patterson DE, Segura JW. Ureteroscopy: current practice and longterm complications. J Urol. 1997; 157: 28-32.

22. Delepaul B, Lang $H$, Abram F, saussine $C$, Jacqmin D. Ureteroscopy for ureteral calculi. 379 cases. Prog Urol. 1997; 7: 600-603.

23. Yaycioglu $O$, Guvel $S$, Kilinc $F$, Egilmez $T$, Ozakardes H. Results with $7.5 \mathrm{~F}$ versus $10 \mathrm{~F}$ rigid ureteroscopes in treatment of ureteral calculi. Urology 2004; 64: 643-6.

24. Khan AA, Hussain SA, Khan N, et al. Safety and efficacy of ureteroscopic pneumatic lithotripsy. JCPSP. 2011; 21:616-19.

25. Martin X, Ndoye A, Konan PG, Feitosa Tajra LC, Gelet A, Dawahra M, Dubernard JM. Hazards of lumbar ureteroscopy: a propose of 3 cases of avulsion of the ureter. Prog urol. 1998; 8:358-362. 